\title{
Economic Evaluation of ESS in Urban Railway Substation for Peak Load Shaving Based on Net Present Value
}

\author{
Jong-young Park*, Jae-Haeng Heo ${ }^{\dagger}$, Seungkwon Shin* and Hyungchul Kim*
}

\begin{abstract}
In this paper, we estimate the economic benefits of Energy Storage Systems (ESSs) for peak load shaving in an urban railway substation using the annual cost. The annual investment cost of ESSs is estimated using Net Present Value (NPV) and compared with the cost reduction of electricity by the ESS. The optimal capacities of the battery and Power Converting System (PCS) are determined for peak load shaving. The optimal capacity of the ESS and the peak load shaving is determined to maximize the profit by the ESS. The proposed method was applied to real load data in an urban railway substation, and the results show that electric power costs can be reduced. Other aspects of the ESS, such as the lifetime and unit price of the battery, are also investigated economically.
\end{abstract}

Keywords: ESS, Peak load shaving, Economic evaluation, NPV, Urban railway

\section{Introduction}

In electric power systems, an electric energy storage system (ESS) is used widely for various purposes. To enable renewable energy sources (RESs), such as solar and wind power, ESSs are applied to power systems for various purposes. ESSs reduce the uncertainty in the operation of RESs [1] and make it possible to accommodate high penetration levels of RESs [2]. The authors in [3] proposed a method to determine the optimal ESS operation to increase the value of wind-power generation.

ESSs also improve the system reliability of microgrids. ESSs provide power to island systems during planned or unplanned network outages [4]. Microgrids can be expanded efficiently by load management and mitigating power quality issues [5]. Research studies were performed to find the optimal size of an ESS for isolated microgrid operation in $[6,7]$.

At the same time, the cost-efficient operation of the distribution systems has become a greater concern as smart grids have been developed and deployed. ESS is one of the promising technologies to improve the reliability and efficiency of distribution systems. ESSs can be applied to distribution substations to achieve benefits such as upgrade deferral and arbitrage benefit maximization [8,9]. The authors in [10] predicted the peak load based on the record of load and reduced the peak load by the stored energy during the predicted peak-load period. ESSs can also be used to flatten the electrical load by charging and discharging [11]. The operation schedule of ESSs was determined based on the recorded load data for load leveling, frequency regulation, arbitrage, peak load shaving,

$\dagger$ Corresponding Author: Power System Research Team, Master's Space Co. Ltd., Korea. (jypark@krri.re.kr)

* Smart Station Research Team, Korea Railroad Research Institute, Korea.

Received: July 18, 2016; Accepted: January 11, 2017 and integration of renewable power generation in [12]. ESSs were applied to the residential distribution feeder to reduce the peak load in [13]. The authors in [14] proposed a method to determine the optimal size of an ESS to maximize economic benefits by reducing the electricity price while minimizing investment costs. They also proposed a strategy to minimize energy costs using dynamic programming. The authors in [15] proposed a comprehensive planning framework to find the optimal siting and sizing of ESSs in distribution networks to maximize benefits. Furthermore, they adopted a probabilistic approach to determine the optimal operation of ESSs at each load state.

This paper proposes an economic evaluation method for an ESS in an urban railway substation for peak load shaving. The electrical load of an urban railway has different characteristics from a normal electrical load. The peak load periods are the rush hours in the morning and evening, which are different from those of the normal electric load. In addition, the change of electrical loads in urban railway substations is more periodic than normal loads because of the punctuality of subway trains. These characteristics enable the reduction of electricity costs by shaving the peak load using an ESS. On the other hand, an ESS is associated with installation and maintenance costs. Consequently, the net profit of an ESS is determined by its economic benefit and investment cost.

In this paper, we calculate the reduction of the electricity cost and the annual investment cost using the net present value (NPV) method and find the maximum profit of the ESS. The optimal capacities of the battery and power converting system (PCS) are determined by the algorithm introduced in [16] based on the load data of the substation, which considers the characteristics of the battery and PCS, such as installation cost, maintenance cost, lifetime, and round-trip efficiency, and finds the capacities of the battery 
and PCS to maximize the annual profit. The proposed algorithm is validated with the real load data of a substation in an urban railway. In addition, the effects of the various aspects of the battery in the ESS are analyzed to evaluate the ESS economically.

\section{Capacity Determination of ESS for Peak Load Shaving}

It is important to properly determine the capacities of the battery and PCS for peak load shaving with the ESS. The optimal capacity of the ESS is closely related with the daily load curve and the target peak load. In this paper, we use the capacity determination method introduced in [16] as follows.

Firstly, the optimal capacity of the battery for the ESS with the target peak load $P_{\text {peak }}^{E S S}$ is calculated based on daily load curves in the urban railway substation. Fig. 1 shows an example of a daily load curve used to calculate the battery capacity made from hourly measured data. To reduce the peak load by $P_{\text {shaving, }}$, which means to shift loads above base load $P_{\text {peak }}^{E S S}$ to under that value, the required storage capacity of the battery is $W_{\text {battery, which is }}$ calculated from (1) - (2).

$$
\begin{aligned}
W_{\text {battery }}\left(\Delta P_{\text {peak }}\right) & =\frac{1}{\varepsilon} \cdot \sum_{i=1}^{24} f\left(P_{\text {load }, i}-\left(P_{\text {peak }}-\Delta P_{\text {peak }}\right)\right) \\
& =\frac{1}{\varepsilon} \cdot \sum_{i=1}^{24} f\left(P_{\text {load }, i}-P_{\text {peak }}^{E S S}\right) \\
& =\frac{1}{\varepsilon} \cdot \sum_{i=1}^{24} P_{\text {shaving }, i}
\end{aligned}
$$

such that

$$
W_{\text {battery }}<\frac{1}{\varepsilon} \cdot \sum_{i=1}^{24} f\left(P_{\text {load }, i}-P_{\text {peak }}^{E S S}\right)
$$

where

$$
f(a)= \begin{cases}a & \text { if } a>0 \\ 0 & \text { if } a \leq 0\end{cases}
$$

$$
\begin{array}{ll}
\varepsilon & : \text { round-trip efficiency of ESS } \\
W_{\text {battery }} & : \text { capacity of battery }[\mathrm{kWh}] \\
P_{\text {load, } i} & : \text { amount of load at time } i[\mathrm{~kW}] \\
P_{\text {peak }}^{E S S} & : \text { target peak load with ESS }[\mathrm{kW}] \\
P_{\text {shaving, } i} & : \text { amount of load shaving at time } i[\mathrm{~kW}] \\
P_{\text {peak }} & : \text { peak load shaving by ESS }[\mathrm{kW}]
\end{array}
$$

The required capacity of the PCS can be determined according to the battery capacity, $W_{\text {battery, }}$ of the ESS. If the peak load over the time period, such as 15 minutes, is measured from the accumulated power consumption, as

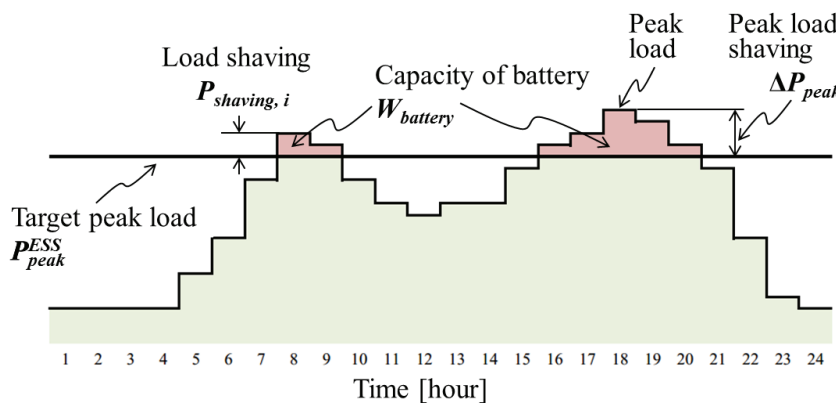

Fig. 1. Daily load curve of urban railway substation and required capacity of battery

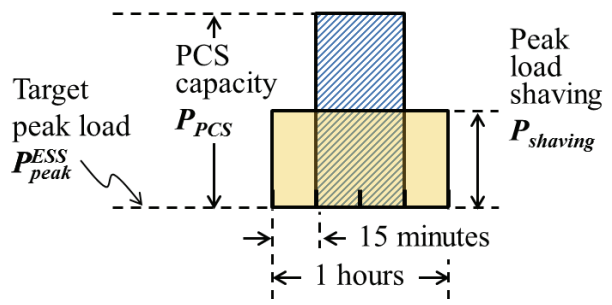

Fig. 2. Case of largest capacity of PCS of ESS when measuring period is 15 minutes

shown in Fig. 2, the required capacity of the PCS is the largest. In this case, in just 15 minutes, the battery discharges all of the energy that is considered to be discharged during one hour when the battery's capacity is determined.

The required capacity of the PCS, $P_{P C S}$, for $n_{\text {mea }}$ minute measurements is described in (3).

$$
P_{P C S}\left(\Delta P_{\text {peak }}\right)=\frac{60}{2 n_{\text {mea }}} \cdot P_{\text {shaving }}^{M A X}\left(\Delta P_{\text {peak }}\right)
$$

where

$$
\begin{array}{ll}
P_{P C S} & : \text { capacity of PCS }[\mathrm{kW}] \\
n_{\text {mea }} & : \text { time period for peak load measuring [min.] } \\
P_{\text {shaving }}^{\text {MAX }} & : \text { maximum amount of load shaving }[\mathrm{kW}] \\
\Delta P_{\text {peak }} & : \text { peak load shaving by ESS }[\mathrm{kW}]
\end{array}
$$

\section{Economic Evaluation Method for ESS}

\subsection{Annual investment cost of ESS equipment}

The investment cost in the ESS is the sum of installation and maintenance costs. In this paper, to evaluate the economic effects of ESSs, the investment cost is annualized with the assumption that the ESS equipment is installed repeatedly after its expected service life. The NPV of the installation and maintenance is compared with that of the annualized investment cost for the entire usage period.

Eqs. (4) and (5) represent the NPV of the installation and 
maintenance costs of the ESS, respectively. The relation between the total investment cost and the annual investment cost of the ESS is shown in Eq. (6). Thus, the annual investment cost of ESS equipment can be represented by the installation cost and maintenance cost by (7).

$$
\begin{gathered}
C_{\text {inst }}^{\text {total }}\left(\Delta P_{\text {peak }}\right) \\
=C_{\text {inst }}+C_{\text {inst }}\left(\frac{1}{1+r}\right)^{N}+C_{\text {inst }}\left(\frac{1}{1+r}\right)^{2 N}+\cdots \\
=C_{\text {inst }}\left(1+R^{N}+R^{2 N}+\cdots\right)=\frac{C_{\text {inst }}}{1-R^{N}} \\
C_{\text {mntn }}^{\text {total }}\left(\Delta P_{\text {peak }}\right)=C_{\text {mntn }}\left(1+R^{1}+R^{2}+\cdots\right)=\frac{C_{\text {mntn }}}{1-R} \\
C^{\text {total }}\left(\Delta P_{\text {peak }}\right)=C_{\text {inst }}^{\text {total }}\left(\Delta P_{\text {peak }}\right)+C_{\text {mntn }}^{\text {total }}\left(\Delta P_{\text {peak }}\right) \\
=C^{\text {ann }}\left(R+R^{2}+R^{3}+\cdots\right)=C^{\text {ann }}\left(\Delta P_{\text {peak }}\right)\left(\frac{R}{1-R}\right) \\
C^{\text {ann }}\left(\Delta P_{\text {peak }}\right)=\frac{1-R}{R\left(1-R^{N}\right)} C_{\text {inst }}+C_{\text {mntn }}
\end{gathered}
$$

where

$$
\begin{array}{ll}
r & : \text { discount rate },\left(R=\frac{1}{1+r}\right) \\
N & : \text { expected service life of device } \\
C_{\text {inst }}^{\text {total }} & : \text { total installation cost } \\
C_{\text {mnth }}^{\text {tota }} & : \text { total maintenance cost } \\
C_{\text {inst }} & : \text { installation cost of device } \\
C_{m n t n} & : \text { annual maintenance cost of device } \\
C^{\text {ann }} & : \text { annualized cost of device } \\
\Delta P_{\text {peak }} & : \text { peak load shaving by ESS }[\mathrm{kW}]
\end{array}
$$

\subsection{Cost reduction by ESS}

The electricity fee generally consists of the base fee and the usage fee. In Korea, the base fee is related with the peak load, and the usage fee is proportional to the amount of energy used. Table 1 shows a case of the electricity price

Table 1. Electricity price of KEPCO

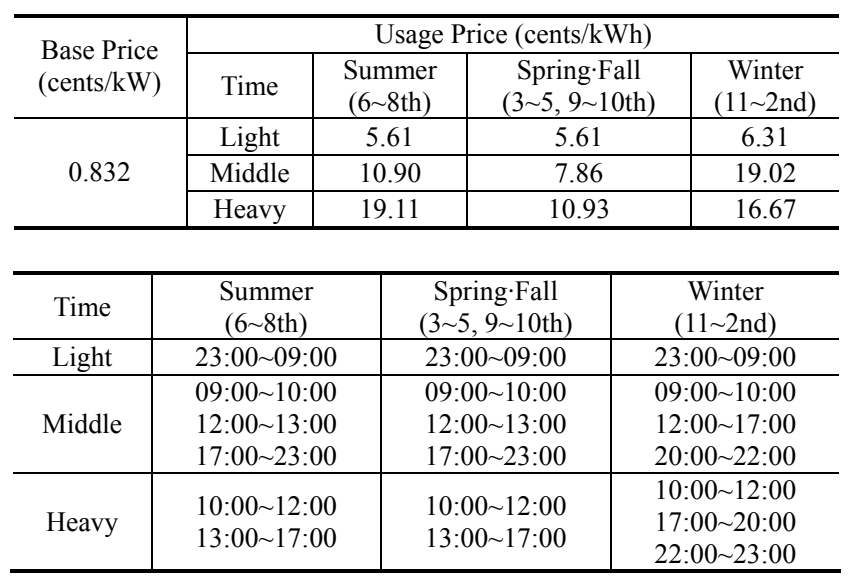

based on that of the Korea Electric Power Corporation (KEPCO).

The reduction of the electricity cost by the ESS also consists of the reductions of the base fee and usage fee. When the ESS with the battery of capacity $W_{\text {battery }}$ is applied, the amount of peak load is $P_{\text {peak }}^{E S S}$ in (1), so that the base fee without the ESS ( $F_{\text {base }}$ ) and that with the ESS $\left(F_{\text {base }}^{E S S}\right)$ are as shown in $(8)-(9)$.

$$
\begin{gathered}
F_{\text {base }}=\rho_{\text {base }} \cdot P_{\text {peak }} \\
F_{\text {base }}^{\text {ESS }}=\rho_{\text {base }} \cdot P_{\text {peak }}^{\text {ESS }}
\end{gathered}
$$

where

$$
\begin{aligned}
F_{\text {base }} & : \text { monthly base fee without ESS }[\$] \\
F_{\text {base }}^{E S S} & : \text { monthly base fee with ESS }[\$] \\
\rho_{\text {base }} & : \text { unit price for base price }[\$ / \mathrm{kWh}] \\
P_{\text {peak }} & : \text { annual peak load without ESS }[\mathrm{kW}] \\
P_{\text {peak }}^{E S S} & : \text { annual peak load with ESS }[\mathrm{kW}] \text { (target amount } \\
& \text { of peak load with ESS) }
\end{aligned}
$$

On a day when the peak load is not high, the installed ESS can be used to reduce the electricity consumption during the expensive hours in the day; on the other hand, the round-trip efficiency of the ESS should be considered in calculating the benefits of the ESS. Considering these aspects, the remaining storage capacity of the battery after peak shaving can be used to reduce the usage fee when the peak load during a day is lower than the target peak load, which is formulated as shown in (10) - (12).

$$
\begin{gathered}
W_{\text {usage }}=W_{\text {battery }}-W_{\text {peak }} \\
=W_{\text {battery }}-\sum_{i=1}^{24} f\left(P_{\text {load }, i}-P_{\text {peak }}^{E S S}\right) \\
F_{\text {usage }}=\sum_{j=1}^{M} \sum_{i=1}^{24}\left(\rho_{i} \times P_{\text {load }, i}\right) \\
=F_{\text {usage }}-\sum_{j=1}^{M}\left\{\rho_{\text {usage }}^{\text {MAX }} \cdot \varepsilon W_{\text {usage }}-\rho_{\text {usage }}^{\text {MIN }} \cdot W_{\text {usage }}\right\}
\end{gathered}
$$$$
F_{\text {usage }}^{\text {ESS }}\left(\Delta P_{\text {peak }}\right)
$$

where

$W_{\text {usage }}$ : capacity of battery used to reduce usage price in a day

$W_{\text {peak }}$ : capacity of battery used to reduce peak load in a day

$M \quad$ : number of days in a month

$F_{\text {usage }}:$ monthly usage fee without ESS [\$]

$F_{\text {usage }}^{\text {ESS }}:$ monthly usage fee with ESS [\$]

$\varepsilon \quad$ : round-trip efficiency of ESS 
$\rho_{i} \quad$ : unit price for time $i \quad[\$ / \mathrm{kWh}]$

$\rho_{\text {usage }}^{\text {MAX }}:$ maximum unit price in a day $[\$ / \mathrm{kWh}]$

$\rho_{\text {usage }}^{M I N}:$ minimum unit price in a day $[\$ / \mathrm{kWh}]$

Therefore, the annual cost reduction of electricity by the ESS, $R^{a n n}$, can be calculated as shown in (13).

$$
\begin{aligned}
R^{\text {ann }}\left(\Delta P_{\text {peak }}\right) & \\
= & \sum_{k=1}^{12}\left\{\left(F_{\text {base }}-F_{\text {base }}^{E S S}\right)+\left(F_{\text {usage }}-F_{\text {usage }}^{E S S}\right)\right\} \\
& =12 \rho_{\text {base }} \cdot\left(P_{\text {peak }}-P_{\text {peak }}^{E S S}\right)+\sum_{k=1}^{12}\left(F_{\text {usage }}-F_{\text {usage }}^{E S S}\right) \\
& =12 \rho_{\text {base }} \cdot \Delta P_{\text {peak }}+\sum_{k=1}^{12}\left(F_{\text {usage }}-F_{\text {usage }}^{E S S}\left(\Delta P_{\text {peak }}\right)\right)
\end{aligned}
$$

where

$$
\begin{aligned}
& R^{a n n} \quad: \text { annual cost reduction of electricity by ESS } \\
& \Delta P_{\text {peak }}: \text { peak load shaving by ESS }[\mathrm{kW}] \\
& k \quad: \text { months }(1, \ldots, 12)
\end{aligned}
$$

\subsection{Determination of optimal capacities}

The optimal capacities of the battery and PCS of the ESS can be determined by comparing the annual investment costs and benefits of the ESS, which are introduced in sections 3.2 and 3.3.

After determining the deviation of the peak load, $\Delta P_{\text {peak }}$, the capacities of the battery and PCS, denoted respectively by $W_{\text {battery }}$ and $P_{P C S}$, are determined by (1) and (3), which is followed by determining the capacity, $W_{\text {usage, }}$ used to reduce the usage price by (10). The installation and maintenance cost of the ESS in (7) has a relation with $W_{\text {battery }}$ and $P_{P C S}$, which are determined by $\Delta P_{\text {peak }}$, so that the annual investment cost, $C^{a n n}$, in (7) is formulated as a function of $\Delta P_{\text {peak }}$, as shown in (14). The annual cost reduction of electricity by the $\mathrm{ESS}, R^{a n n}$, is also formulated as a function of the $\Delta P_{\text {peak }}$, as shown in (15), by the same process used with the $C^{a n n}$.

$$
\begin{aligned}
C^{a n n} & =C^{a n n}\left(\Delta P_{\text {peak }}\right) \\
R^{a n n} & =R^{a n n}\left(\Delta P_{\text {peak }}\right)
\end{aligned}
$$

Eq. (16) calculates the optimal amount of peak load shaving to maximize the profit by the ESS.

$$
\max _{\Delta P_{\text {peak }}}\left[R^{a n n}\left(\Delta P_{\text {peak }}\right)-C^{a n n}\left(\Delta P_{\text {peak }}\right)\right]
$$

Then, the optimal capacities of the battery and PCS are determined by (1) and (3), respectively.

\section{Case Study}

\subsection{Load data of urban railway system}

Analysis of the loads in the urban railway substation is important to evaluate the ESS economically for peak load shaving. For this purpose, we analyzed the actual load data of an urban railway substation in Korea during the year 2013 [16]. Figures 3 depicts the daily load curves of the urban railway substation on weekdays and weekends, respectively; the loads on weekdays are the averages in each month, and those on weekends are the averages in each season (spring: $3 \sim 5^{\text {th }}$, summer: $6 \sim 8^{\text {th }}$, fall: $9 \sim 10^{\text {th }}$, and winter: $\left.11 \sim 2^{\text {nd }}\right)$. It was assumed that the interest rate was $3 \%$ in the simulations.

From Fig. 3, we can see that the peak load period is located at around 9 a.m. and 8 p.m. during rush hour, whereas the peak load period is located at around noon in the whole power system. This difference between the urban railway and the whole power system can be utilized in the economic operation of the ESS.

\subsection{Economic evaluation of ESS}

The optimal capacities of the battery and PCS in the ESS were calculated with the load data in section 4.1 and the electricity fees of Table 1 . The other conditions for the ESS in the case study are presented in Table 2. The constrained number of charge/discharge cycles of ESS is assumed one in simulations.

To find the optimal capacity, the amount of peak load shaving $\Delta P_{\text {peak }}$ in (16) that maximizes the annual profit was firstly calculated. Fig. 4 shows the annual profit according to the variation of the peak shaving. With peak load

Table 2. Conditions for ESS in case study

\begin{tabular}{c|c|c|c|c}
\hline & Unit price & Lifetime & $\begin{array}{c}\text { Maintenance } \\
\text { Cost }\end{array}$ & $\begin{array}{c}\text { Round-trip } \\
\text { Efficiency }\end{array}$ \\
\hline Battery & $100 \$ / \mathrm{kWh}$ & 7 years & $6 \$ / \mathrm{kWh}$ & $95 \%$ \\
\hline PCS & $80 \$ / \mathrm{kW}$ & 15 years & $4 \$ / \mathrm{kW}$ & - \\
\hline
\end{tabular}

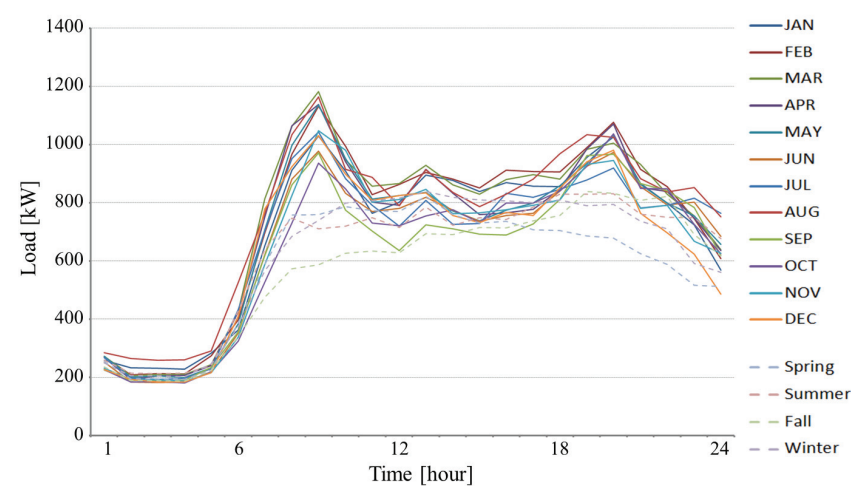

Fig. 3 Daily load curve of urban railway substation 
Table 3. Annual electricity costs with and without ESS with optimal peak shaving amount

\begin{tabular}{c|c|c|c}
\hline & Base Fee & Usage Fee & Total \\
\hline w/ ESS & $\$ 133,754$ & $\$ 606,507$ & $\$ 740,261$ \\
\hline w/o ESS & $\$ 115,283$ & $\$ 606,304$ & $\$ 721,587$ \\
\hline
\end{tabular}

Table 4. Optimal capacities of battery and PCS of ESS

\begin{tabular}{c|c}
\hline Battery & $320 \mathrm{kWh}$ \\
\hline PCS & $640 \mathrm{~kW}$ \\
\hline
\end{tabular}

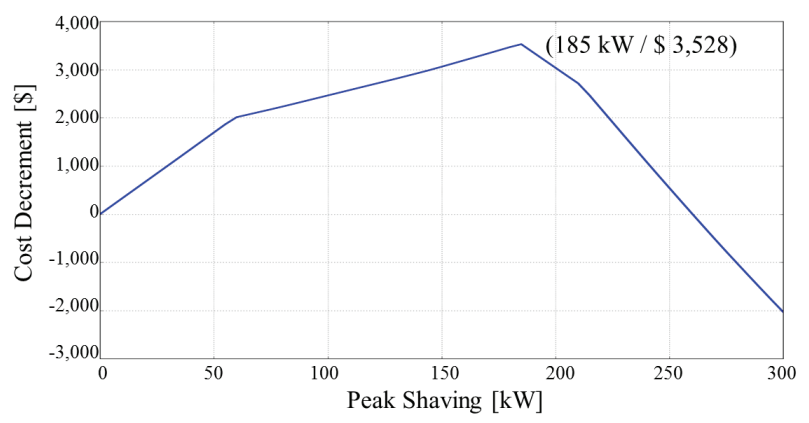

Fig. 4. Annual profit by ESS according to peak load shaving

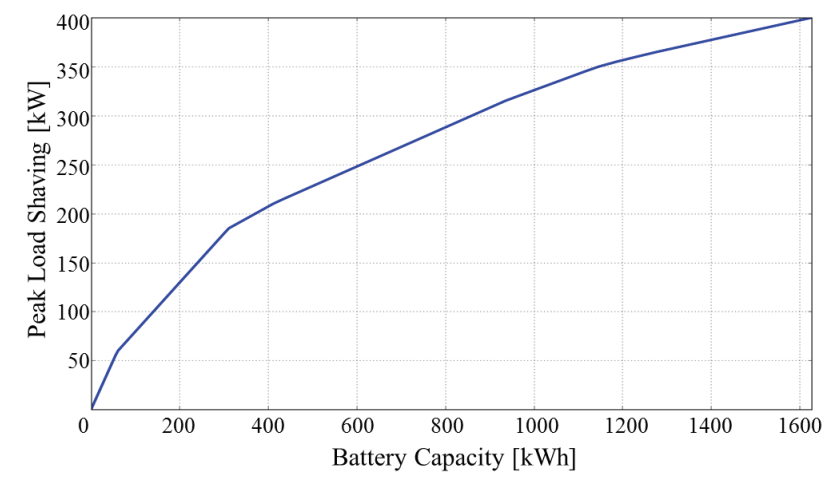

Fig. 5. Possible amount of peak load shaving according to storage capacity of battery

shaving of $185 \mathrm{~kW}$, the annual profit is maximized and the electricity cost is reduced by $\$ 3,528$ per year. Table 3 shows the electricity costs with and without the ESS with the optimal peak load shaving.

With the optimal peak load shaving, the capacities of the battery and PCS were determined by (1) and (3), respectively. Table 4 shows the optimal capacities of the battery and PCS.

The ESS reduces the electricity cost mainly by peak load shaving, which is achieved by the charge and discharge of the battery. Therefore, the efficiency analysis and the economic evaluation of the battery are important in the economic evaluation of the ESS.

Firstly, the battery's efficiency of the peak load shaving is investigated. Fig. 5 shows the possible amount of peak load shaving according to the storage capacity of the

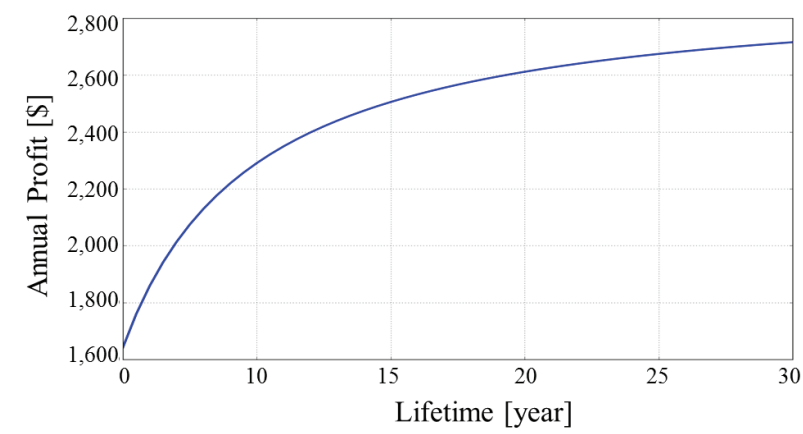

Fig. 6. Annual profits of ESS according to lifetime of battery

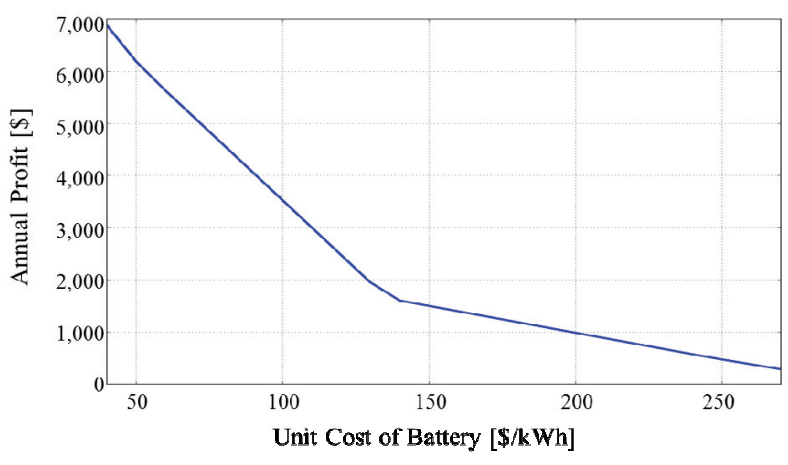

Fig. 7. Annual profit according to unit cost of battery

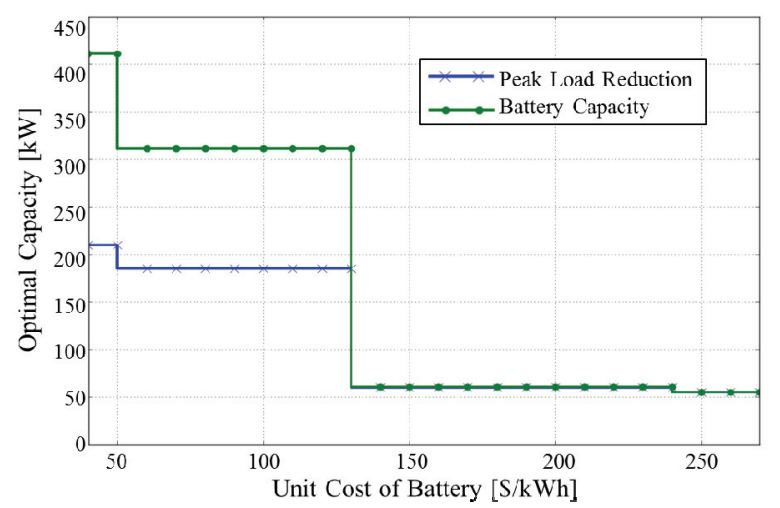

Fig. 8. Optimal capacity of battery and peak load decrease in accordance with unit cost of battery

battery in the ESS. The change per kWh of peak load with $50 \mathrm{kWh}$ battery storage is $1.00 \mathrm{~kW} / \mathrm{kWh}$, whereas it is 0.20 $\mathrm{kW} / \mathrm{kWh}$ with a $500-\mathrm{kWh}$ battery. This indicates that the larger the storage capacity of the battery becomes, the lower the efficiency of reducing peak load is.

Fig. 6 presents the annual profit of the ESS according to the change of the lifetime of the battery in the ESS. The annual profit becomes larger as the lifetime of the battery becomes longer, while the change amount of the annual profit becomes smaller. When the lifetime of the battery is 8.5 years, the increase of the profit is $10 \%$ of the annual profit as the lifetime of the battery increases by one year. Consequently, a lifetime of more than nine years is reasonable for a battery from an economic viewpoint. 
On the other hand, the effect of the price of the battery is investigated. Fig. 7 shows the annual profit, and Fig. 8 shows the optimal capacity of the battery and the peak load decrease according to the unit cost of the battery.

The annual profit increases by $\$ 50$ when the unit cost of the battery is lowered by $\$ 1$ for a unit cost less than $130 \$ / \mathrm{kWh}$, whereas it increases by $\$ 10$ for a unit cost higher than that value. The optimal amount of peak load determined by (16) becomes lower as the unit price of the battery becomes higher. The optimal peak load decrease is $60 \mathrm{~kW}$ for a unit cost of more than $130 \$ / \mathrm{kWh}$ and $185 \mathrm{~kW}$ for the other condition.

\section{Conclusions}

An ESS can be used to reduce the electricity costs in a distribution system by peak load shaving. We proposed an evaluation method for an ESS in an urban railway substation for peak load shaving. The electrical load of the urban railway has a different peak load period from the whole power system, and it is more periodic than the normal load. These characteristics can be used to reduce the electricity costs by the ESS.

In the proposed algorithm, the peak load shaving amount determines the reduction of the electricity cost. The capacities of the battery and PCS are consequently calculated by the peak load shaving amount, followed by the investment cost of the ESS. The annual investment cost is calculated by the NPV. The optimal capacity of the ESS and the peak load shaving is determined to maximize the profit, which is the difference between the annual cost reduction of electricity and the annual investment cost of the ESS.

The ESS was evaluated economically using the proposed algorithm based on the real data of an urban railway substation. The optimal capacity of the ESS and the profit from it were calculated, and other aspects were also investigated. The battery's efficiency of the peak load shaving became lower as the storage capacity of the battery became larger. In the simulations, an ESS lifetime of more than nine years was found to be economically reasonable, and the optimal capacity of the battery changed when the unit price of the battery was $130 \$ / \mathrm{kWh}$. The proposed evaluation method can also be applied to general distribution substations for the economic evaluation of ESSs.

\section{Acknowledgements}

This research was supported by a grant from R\&D Program of the Korea Railroad Research Institute, Republic of Korea

\section{References}

[1] H. Bludszuweit and J. A. Dominguez-Navarro, "A probabilistic method for energy storage sizing based on wind power forecast uncertainty," IEEE Trans. Power Syst., vol. 26, no. 3, pp. 1651-1658, Aug. 2011.

[2] Y. M. Atwa and E. F. El-Saadany, "Optimal allocation of ESS in distribution systems with a high penetration of wind energy," IEEE Trans. Power Syst., vol. 25, no. 4, pp. 1815-1822, Nov. 2010.

[3] M. Korpaas, A. T. Holen, and R. Hildrum, "Operation and sizing of energy storage for wind power plants in a market system," Int. J. Elect. Power Energy Syst., vol. 25, pp. 599-606, Oct. 2003.

[4] IEEE Guide for Design, Operation, and Integration of Distributed Resource Island Systems With Electric Power Systems, IEEE Standard 1547.4-2011, 2011.

[5] C. Chen, S. Duan, T. Cai, B. Liu, and G. Hu, "Optimal allocation and economic analysis of energy storage system in microgrids," IEEE Trans. Power Electron., vol. 26, no. 10, pp. 2762-2773, Oct. 2011.

[6] C. Abbey and G. Joos, "A stochastic optimization approach to rating of energy storage systems in winddiesel isolated grids," IEEE Trans. Power Syst., vol. 24, no. 1, pp. 418-426, Feb. 2009.

[7] S. X. Chen, H. B. Gooi, and M. Q. Wang, "Sizing of energy storage for microgrids," IEEE Trans. Smart Grid, vol. 3, no. 1, pp. 142-151, Mar. 2012.

[8] F. A. Chacra, P. Bastard, G. Fleury, and R. Clavreul, "Impact of energy storage costs on economical performance in a distribution substation," IEEE Trans. Power Syst., vol. 20, no. 2, pp. 684-691, May 2005.

[9] R.-C. Leou, "An economic analysis model for the energy storage system applied to a distribution substation," Int. J. Elect. Power Energy Syst., vol. 34, pp. 132-137, Jan. 2012.

[10] S. G. Deshpande and L. J. Kerofsky, "System and method for energy storage management," US Patent No. 2013/0274935 A1, 2013.

[11] R. Kerestes, G. Reed, and A. Sparacino, "Economic analysis of grid level energy storage for the application of load leveling," Power and Energy Society General Meeting, pp. 1-9, 2012 IEEE, July 2012.

[12] A. Paice, A. Oudalov, and T. Von Hoff, "Method for operating an energy storage system," US Patent No.8493030 / European Patent No. EP2190097, 2013.

[13] C. Venu, Y. Riffonneau, S. Bacha, and Y. Baghzouz, "Battery storage system sizing in distribution feeders with distributed photovoltaic systems," PowerTech, 2009 IEEE Bucharest, pp. 1-5, June 2009.

[14] A. Oudalov, R. Cherkaoui, and A. Beguin, "Sizing and optimal operation of battery energy storage system for peak shaving application," Power Tech, 2007 IEEE Lausanne, pp. 621-625, July 2007.

[15] Ahmed S. A. Awad, Tarek H. M. EL-Fouly, and Magdy M. A. Salama, "Optimal ESS allocation for 
benefit maximization in distribution networks," IEEE Trans. Smart Grid, Issue 99, pp. 1-11, Nov. 2015.

[16] Jong-young Park, Hosung Jung, Hyungchul Kim, and Seungkwon Shin, "Capacity determination of ESS for peak load shaving based on the actual measurement of loads in the substation of urban railway," Trans.of KIEE, vol. 63, no. 6, pp. 860-865, May 2014.

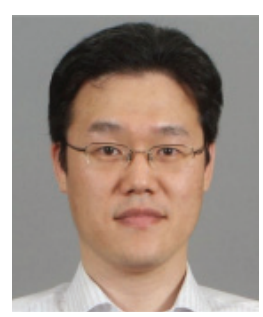

Jong-young Park He received his B.S., M.S., and Ph.D. degrees from Seoul National University, Seoul, Korea, in 1999, 2001, and 2007, respectively. He was a Senior Researcher at LSIS Co., Ltd., Korea from 2009 to 2013. Currently, he is a Senior Researcher at Korea Railroad Research Institute (KRRI). His recent research interests include the optimal operation of power systems in railway with the smart grid technology.

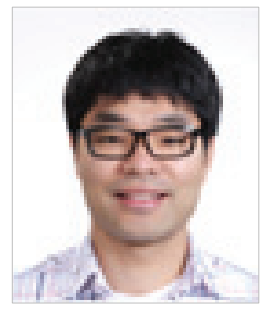

Jae-Haeng Heo He received his Ph.D. degree in Electrical Engineering from Seoul National University, Seoul, Korea in 2012. He was a research professor at Chonbuk National University, Korea. Currently, he works at the MasterSpace that is a consulting company for the power system and power system economics. His research field of interest includes power system reliability, equipment maintenance and urban railroad.

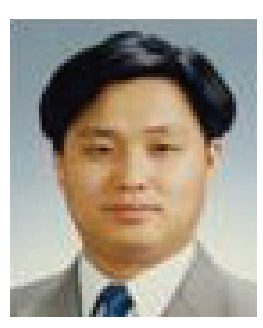

Seungkwon Shin He received his B.S., M.S. degree in Electrical Engineering and $\mathrm{Ph}$. D degree in School of Electrical and Computer Engineering from Sungkyun-kwan University, Korea, in 1995, 1998 and 2001, respectively. Currently, he is a Senior Researcher in Korea Railroad Research Institute (KRRI). His research interests include a power electronic control and a railway substation including power quality, measurement and detection.

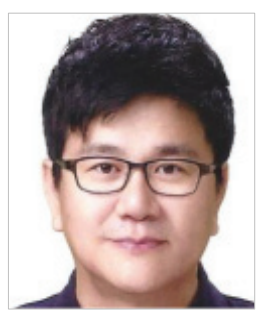

Hyungchul Kim $\mathrm{He}$ received his BS and MS degree in Electrical Engineering from Korea University, Seoul, Korea in February 1991 and in February 1993 respectively. He then worked for LG electronics Inc. for 6 years. He received a Ph.D. degree from Texas A\&M University in August 2003.

Currently, He is working for Korea Railroad Research Institute. His research area is traction power system and power system reliability. 